Session 3566

\title{
Crossing Course Boundaries: A Joint Class Project between Machine Component Design and Manufacturing Processes Courses
}

\author{
Jon H. Marvel, Wendy Reffeor \\ Padnos School of Engineering, Grand Valley State University
}

\section{Introduction}

A requirement of all mechanical engineering majors in the Padnos School of Engineering, Grand Valley State University is a course in Machine Component Design. This course is normally taken in the second semester of the senior year. During the same semester, most of the mechanical engineering students will take an elective course in Manufacturing Processes. A semester project, typically a design and build, is required in each of these courses. An initiative was undertaken to integrate these two semester projects into one project that captured the integrative approach of the product development process.

In the Manufacturing Processes course, one of the primary objectives is for the student to be able to select and discriminate between a variety of manufacturing processes and parameters and have the ability to fabricate uncomplicated parts using manual lathes, mills and/or welding processes. During the course the student's are exposed to a wide variety of manufacturing processes which traditionally start with the metal material removal process and progress to joining, fastening, metal forming, casting, plastics molding and conclude with nontraditional processes. In order to supplement the lecture portion of the course, laboratory experiments provide the students with practical experience operating and analyzing the effects of the parameters of a variety of equipment, including standard manual mills, lathes, and several welding processes. The final component of the course is for the students to demonstrate their abilities to design and fabricate a simple component utilizing a variety of manufacturing processes.

In the Machine Component Design course, students are introduced to many machine components such as shafts, bearings, gears, springs, clutches and brakes, chains and belts, threaded fasteners and power screws. One of the primary objectives of the course is for students to not only be able to analyze these components, but also develop an understanding of how components work together in a system. To meet this objective, students are required to complete a design and build a project utilizing a minimum of two of the components discussed in the course.

\section{Project Requirements}

The integrated project for these courses was based on the requirements for the RI/SME Robotic Technology and Engineering Challenge - 2001. The students were expected to design and 
fabricate a mechanism based on the product specifications for a manufacturing work cell, articulated robot, or a flexible manufacturing cell as defined in RI/SME Student Robotic Challenge guidelines. During the concept stage the students were required to develop at least three design alternatives and then defend their choice of product design based on design criteria. The focus for the project with regards to the machine component design course was the design and analysis of at least two machine elements. Typical machine elements included gears, bearings, threaded couplings, etc. The students were expected to design the elements based on product specifications and verify these calculations after fabrication and assembly occurred. The focus from the manufacturing processes side was the development of the preliminary CAD models and drawings; both assembly and detail drawings were evaluated and compared to the final product. Additionally, process plans and cost estimates of the final assembly and fabrication were required. Process plans were evaluated based on the initial process plan and the process plan for the as-built mechanism. During the project presentation, team members were required to explain and provide rationale for deviation from the initial process plans. There was a combination of fabricated and purchased parts based on the qualifications of the team members on different equipment. The fabricated parts were generated utilizing available equipment in the manufacturing processes lab including standard manual lathes and mills, welding equipment, and inspection equipment.

The project evaluation was based on the actual product performance, a written report, including all necessary documentation, and an oral presentation by the students. An example of a student project that resulted from this integrative approach was the development of a push diverter sortation conveyor. The machine components designed related to the gearing and coupling on the sortation mechanism while the fabrication of the overall structure as well as the mounting mechanism were developed in fulfillment of the requirement for the manufacturing processes class.

\section{Results}

After evaluating the results from the integration of the project, several strength and weaknesses of this approach were identified. On the benefits side, prior to the capstone project, the students had the opportunity to integrate the knowledge of multiple courses rather than only applying the content of one course to the completion of the project. Since the project was developed from conception to delivery, there was a greater awareness developed of this process. The team size of 5-6 members allowed a significant amount of effort to be expended by the team while the average out of class time spent by the students on this project was less than 45 hours.

Some issues were raised which indicated that modifications to the project format are needed to ensure that the pedagogical objectives of this project are met. The successful completion of this project required a very strict time line with little allowance for poor project management. This was a major cause of a high level of student stress. Requiring the students to de velop the concept of the project, in addition to other course requirements such as exams and laboratory reports, required project proposals to be modified several times in order to prevent the project from becoming a capstone project. Although logbooks were kept regarding the student's participation, there was a large amount of variation of effort, sometimes exceeding 50 hours, between members on the same project team. 


\section{Future Directions}

During the first iteration of the project the student spent several weeks identifying acceptable project concepts and then providing several design alternatives in order to determine the final product that would be delivered. In a 14-week course, spending 3 weeks on this phase of the project severely impacted the available time and due dates for the other activities. An improvement for next integrated project would be to provide the design requirements to the students at the beginning of the course. Although this would eliminate the complete product realization experience from the project, the project was designed to integrate the material from the two courses and not to become a capstone project.

Another area for improvement is related to material acquisition for the fabrication of the product. During the preliminary design phase, the students were not required to use any specific materials for fabrication, but rather given general guidelines. During the early design phases, the students material selection needed to be modified due to either cost or availability issues. This required some modifications to the CAD models to represent the design accurately and additional analysis, such as regenerating the process plans, due to the material changes. Additionally, some of the purchased parts for the machine components, were not standard items and required several weeks for delivery. Since the time was limited, the students needed to re-design the machine components around the available parts. Again, this introduced more delays into the project. Although these types of delays occur in actual engineering practice, the limited time allowed for the project did not allow for these types of interruptions. In order to eliminate this problem in the future, students will be provided an acceptable material list to make their material selections and an approved purchased components list to facilitate the design of their machine components. An example of a specific issue was with the choice of motors. Students were selecting to use servomotors in the case where direct DC motors would have been preferable, especially from a controls standpoint.

The teams consisted of students who were enrolled in either the Manufacturing Process course the Machine Component Design course or both courses concurrently. The make-up of the student teams included each type of student. The inclusion of students who were enrolled in both courses was deemed important in order to provide continuity between the different phases of the project. The expected involvement of the team member was dependent on the whether or not the student was enrolled in only the one or both of the courses concurrently. For students enrolled in both of the courses concurrently, approximately double the effort, as measured by the number of hours logged, was expected since this project satisfied requirements in each of the courses. The issue of the expected amount of effort turned out to affect the group dynamics team and were noted in the team's peer reviews. The actual results indicated that in some cases students enrolled in only one course actually logged more hours than students enrolled in both courses. In order to resolve these issues and promote equity in expected workload, a preferred interaction between the two classes might follow a classical supplier-vendor relationship. The Machine Component Design students would provide detailed drawings to the Manufacturing Process students for fabrication. The fabricated parts would only be accepted if they conformed to the detail drawings. The student teams from each course would not have any members in common in order to ensure an independent supplier-vendor relationship. 
One of the major drawbacks during the first iteration of the integrated project was the strict timetable didn't allow the students to undergo the iterative process of product review and modification. By reducing the time spent by the students on the front end of the concept development, the expected result is that there will be available time for product review and modifications.

\section{Conclusion}

Overall, the evaluation of this project experience indicates that many of the pedagogical objectives were accomplished through the integration of this project between the two courses. The students had a better understanding of the total product realization process and were able to integrate course materials for multiple courses into the same project. Although there were some minor logistical issues, modifications to the overall design of the course project should provide the overall benefits that are desired. Efforts will continue to improve the integration of this project between courses in the future.

JON H. MARVEL

Jon H. Marvel, Ph.D. is an Assistant Professor of Engineering at Grand Valley State University. He holds a BE from Stevens Institute of Technology, an MS from the University of Michigan and a Ph.D. the University of Cincinnati. His is primary responsible for the development of the undergraduate and graduate production operations sequences courses as well as other fundamental courses in the manufacturing engineering curriculum.

\section{WENDY REFFEOR}

Wendy Reffeor, Ph.D. is an Assistant Professor of Engineering at Grand Valley State University. She holds a BS in Mechanical Engineering from GMI Engineering \& Management Institute, an MS in Mechanical Engineering from Purdue University and a Ph.D. from Michigan State University. Since joining GVSU, she has focused on introducing design in traditionally analytical courses in the Engineering Mechanics sequence. 